\title{
Preparation of glass-silver microcomposites by sol-gel route
}

\author{
S DATTA* and G C DAS ${ }^{\dagger}$ \\ Central Glass and Ceramic Research Institute, Calcutta 700032, India \\ ${ }^{\dagger}$ Department of Metallurgical Engineering, Jadavpur University, Calcutta 700032, India \\ MS received 24 October 1991; revised 16 March 1992
}

\begin{abstract}
Glass-silver microcomposites have been prepared through sol-gel route by reducing the gel-containing $\mathrm{AgNO}_{3}$ with alkaline formaldehyde solution. The product has been characterized by atomic absorption spectroscopy and $\mathrm{X}$-ray diffraction technique. Optical spectroscopy of thin films has been studied.
\end{abstract}

Keywords. Sol-gel; microcomposite; silver; reduction; formaldehyde; optical transmittance.

\section{Introduction}

Glass-metal microcomposites have many interesting properties (Das and Chakraborty 1980; Das et al 1983; Datta et al 1984, 1986). Particularly glass-silver particulate composites have been obtained either by exposing the glass to UV radiation followed by subsequent heat treatment (Smithard and Dupree 1972) or by subjecting the glasses to ion exchange with molten $\mathrm{AgNO}_{3}$ followed by reduction with hydrogen (Chakraborty 1974). In this paper we report the results on preparation, characterization and optical studies of glass-silver microcomposites containing about 1-10 wt \% of metallic silver, through the sol gel route by reducing $\mathrm{AgNO}_{3}$ with formaldehyde at about $100^{\circ} \mathrm{C}$.

\section{Experimental}

Table 1 presents the composition of glass-silver microcomposites which have been investigated. $\mathrm{AgNO}_{3}$ (AR grade) in the required quantity was dissolved in $2 \mathrm{ml}$ of deionized water to which $50 \mathrm{ml}$ of ethanol was added followed by addition of $18.6 \mathrm{ml}$ of tetraethyl orthosilicate (TEOS) obtained from BDH, England. The mixture was stirred thoroughly to obtain a homogeneous solution. This was then left for gelation

Table 1. Composition of glass-silver microcomposites with analysis report.

\begin{tabular}{lccccc}
\hline $\begin{array}{l}\text { Sample } \\
\text { no. }\end{array}$ & $\begin{array}{c}\text { TOES } \\
(\mathrm{ml})\end{array}$ & $\begin{array}{c}\text { Deionized } \\
\text { water(ml) }\end{array}$ & $\begin{array}{c}\text { Ethanol } \\
(\mathrm{ml})\end{array}$ & $\begin{array}{c}\text { Silver } \\
\text { nitrate } \\
(\mathrm{gm})\end{array}$ & $\begin{array}{c}\text { Observed } \\
\text { Ag-metal } \\
(\mathbf{w t} \%)\end{array}$ \\
\hline 1 & 18.6 & 2.0 & 50.0 & 0.0945 & 1.2 \\
2 & 18.6 & 2.0 & 50.0 & 0.1575 & 1.75 \\
3 & 18.6 & 2.0 & 50.0 & 0.2408 & 2.6 \\
4 & 18.6 & 2.0 & 50.0 & 0.3935 & 4.7 \\
5 & 18.6 & 2.0 & 50.0 & 0.792 & 9.6 \\
\hline
\end{tabular}

*For correspondence 
at an ambient condition. After a few days the gel became stiff and cracking started. An alkaline solution ( $\mathrm{pH} 9$ to 10 ) of formaldehyde (GR grade, Sarabhai Chemicals) was added in excess to the gel. Vigorous reaction took place with immediate blackening of the gel. To ensure complete reduction of $\mathrm{AgNO}_{3}$ present in the gel it was warmed on a waterbath for 5 to $10 \mathrm{~min}$. It was then removed from water bath, allowed to stand for 2 to $3 \mathrm{~h}$ at room temperature and the gel taken out and washed thoroughly to remove excess formaldehyde, with deionized water. The resulting gel was then dried at $150^{\circ} \mathrm{C}$ for $1 \mathrm{~h}$, whereupon a yellowish gray powder was obtained.

For optical characterization studies, two ultrasonically cleaned glass slides were dip-coated with the respective sol after 2-3 $\mathrm{h}$ of ageing at ambient conditions. These coatings were dried in air and then reduced with $10 \%$ formaldehyde solution at $\mathrm{pH} \sim 10$ at $80^{\circ} \mathrm{C}$ for $1 \mathrm{~h}$. The plates were then taken out and washed carefully in deionized water to free them from excess sol and formaldehydes. The plates were dried in air and optical transmittance was measured from 400 to $900 \mathrm{~nm}$ wavelength in a spectrophotometer (Hitachi model No. V3210). X-ray diffraction patterns for the powdered gel samples were taken with an X-ray diffractometer (PW-100 X-ray crystallographic unit) using $\mathrm{CuK}_{\alpha}$ radiation with $\mathrm{Ni}$ filter. The metallic silver present in all the samples was estimated using an atomic absorption spectrophotometer (Perkin-Elmer-372).

\section{Results and discussion}

Figure 1 shows diffraction patterns of two representative samples (A for sample 2 and $B$ for sample 4) among the samples under investigation. From table 2 it is clear that the computed interplanar spacings ( $d$ values) agree well with the standard $d$ values of metallic silver (Joint Committee on Powder Diffraction Standards, 1967). This suggests the presence of metallic silver in all the composites. Further it was noted from figure 1 that there appeared a broad diffuse peak at $20-22^{\circ}$. The computed value of $d=4.0355$ indicated that this diffuse peak arose from silica gel matrix (Warren and Biscal 1938). The metallic silver present in all the samples was estimated by atomic absorption spectroscopy. The results are presented in table 1.

Figure 1 shows that the relative intensities of the peaks arising from metallic silver

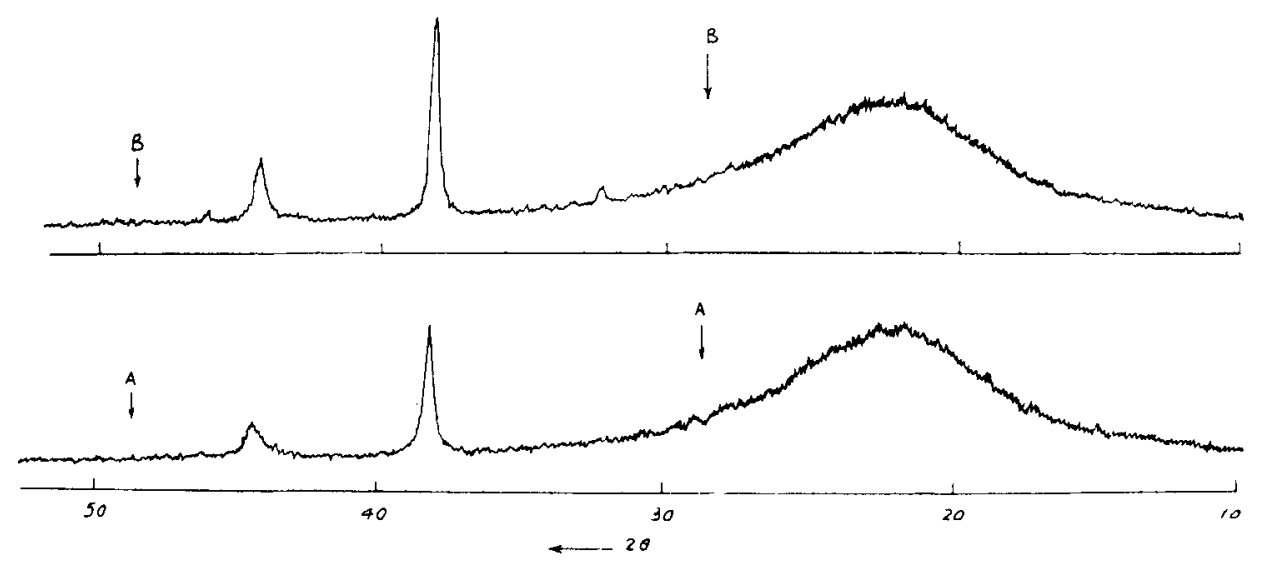

Figure 1. X-ray diffraction patterns (A for sample 2, B for sample 4). 
Table 2. Comparison of computed interplaner spacings $d$ with standard $d$ values of metallic silver.

\begin{tabular}{lc}
\hline $\begin{array}{l}\text { Computed } d \text { values } \\
(\AA)\end{array}$ & $\begin{array}{c}\text { Standard } d \text { values for Ag } \\
(\AA)\end{array}$ \\
\hline 2.352 & $2 \cdot 360$ \\
2.040 & $2 \cdot 040$ \\
\hline
\end{tabular}

phase compared to that of broad peaks of amorphous phase increased from curve $A$ to curve B. This suggests that the quantity of silver present in the composite corresponding to graph $B$ in figure 1 was larger than that in the composite corresponding to graph $\mathrm{A}$. This agrees with the chemical analysis data given in table 1 .

The peaks arising from metallic silver were quite sharp as is evident from figure 1. The approximate particle size of silver metal was calculated using the formula (Cullity 1977) $0 \cdot 9 \lambda / B \cos \theta_{B}$, where $\lambda$ is the monochromatic $X$-ray wavelength, $B$, the width of diffraction curve in radians at an intensity equal to half the maximum intensity and $\theta_{B}$, the Bragg angle in degrees. It was found that the particle size of metallic silver was the same in all the gels $(\sim 210 \AA)$ and was quite reasonable and suited to the model proposed.

The aqueous homogeneous solution of TEOS, $\mathrm{C}_{2} \mathrm{H}_{5} \mathrm{OH}$ and $\mathrm{AgNO}_{3}$ after hydrolysis and polycondensation formed a porous silica gel matrix. Since $\mathrm{AgNO}_{3}$ did not take part in the reaction, it remained in the solution of $\mathrm{C}_{2} \mathrm{H}_{5} \mathrm{OH}$ and water in the pores of the silica gel. This was confirmed when a gel was prepared and instead of reduction with formaldehyde, the gel after solidification was quickly washed twice with $10 \mathrm{ml}$ of distilled water.

The washed gel was then kept in $20 \mathrm{ml}$ of distilled water for 5-10 min. The distilled water was then tested for silver ions with dilute $\mathrm{HCl}$ solution. A thick precipitate of $\mathrm{AgCl}$ confirmed leaching out of silver ions from the gel into water. This happened only if $\mathrm{AgNO}_{3}$ remained in pores but not in the gel network. The reduction of $\mathrm{AgNO}_{3}$ present in the silica gel matrix by alkaline formaldehyde might occur in the same way as in silver mirror test for aldehydes. The reaction which took place was

$$
\stackrel{\mathrm{H}}{\mathrm{H}-\mathrm{C}=\mathrm{O}+2 \mathrm{Ag}^{+}+3 \mathrm{OH}^{-} \rightarrow \mathrm{H}} \stackrel{\|}{\mathrm{C}}-\mathrm{O}^{-}+2 \mathrm{Ag} \downarrow+2 \mathrm{H}_{2} \mathrm{O} .
$$

Alkaline formaldehyde solution diffused through semi-solid silica gel and reacted with $\mathrm{AgNO}_{3}$ solution present in the pores and metallic silver was precipitated in the gel. The reduction of $\mathrm{AgNO}_{3}$ occurred by the addition of formaldehyde and was confirmed by preparing a gel without adding any formaldehyde which gave an almost transparent glassy powder.

Another interesting feature was that the time taken to prepare a stiff gel was strongly dependent on the quantity of silver nitrate added. The gelling time reduced with increasing amount of metallic salt. This was probably due to the catalytic effect of silver nitrate on the hydrolysis and polycondensation of TEOS.

Figure 2 shows a typical optical transmittance spectrum in visible range of the thin film of glass-silver microcomposite. The spectrum showed a peak at around $420 \mathrm{~nm}$, characteristic of metallic silver present in a glassy matrix (Sarkar et al 1983). 


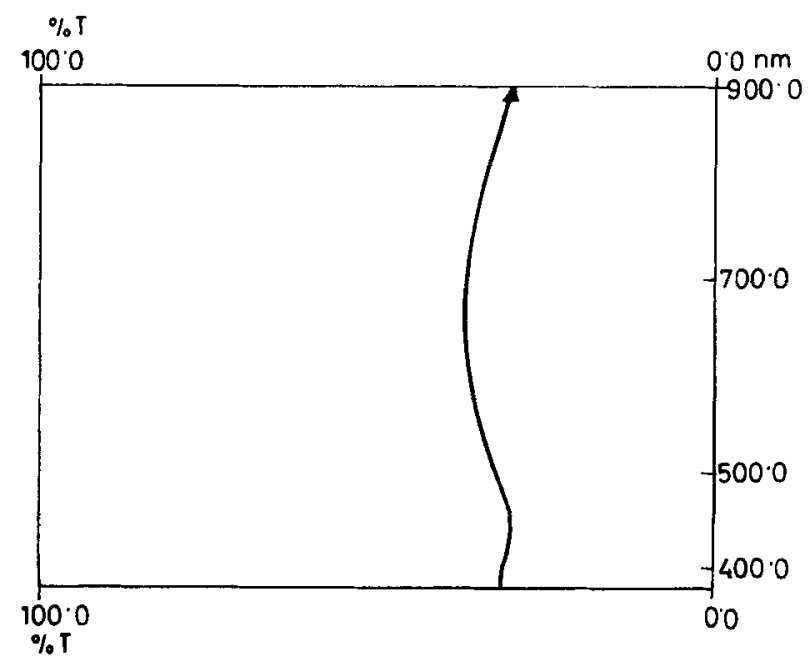

Figure 2. Optical transmittance spectra for sample 5.

\section{Conclusions}

(i) Glass-silver microcomposites containing 1-10 wt \% of metallic silver can be prepared through sol gel route by simple in situ reduction of $\mathrm{AgNO}_{3}$ with formaldehyde.

(ii) The particle size of precipitated metallic silver was independent of the amount of silver nitrate present in the gel and was about $210 \AA$.

(iii) A possible model of the reactions involved has been proposed.

\section{Acknowledgement}

Sincere thanks are due to Mr B Biswas, Dr H S Maiti and Mr D K Ghosh for help rendered in various stages of this investigation.

\section{References}

Chakraborty D 1974 J. Non-Cryst. Solids 15191

Cullity B D 1977 Elements of X-ray diffraction, (London: Addison-Wesley Pub. Co. Inc.) 2nd Ed. p. 284

Das G C and Chakraborty D 1980 J. Appl. Phys. 513896

Das G C, Das R and Chakraborty D 1983 Bull. Mater. Sci. 5277

Datta S, Bahadur D and Chakraborty D 1984 J. Phys. D17 163

Datta S, Mitra S S, Chakraborty D, Ram S and Bahadur D 1986 J. Mater. Sci. Lett. 589

Sarkar P, Kumar J and Chakraborty D 1983 J. Mater. Sci. 18250

Smithard M A and Dupree R 1972 Phys. Status Solidi A111 695

Warren B E and Biscal J 1938 J. Am. Ceram. Soc. 2149 